Keywords: Review, Primary health care, Depression, Treatment outcome, Long term effect.

\title{
Improving long-term outcome of depression in primary care: a review of RCTs with psychological and supportive interventions
}

\author{
Annet Smit ${ }^{\star, * \star}$ \\ Bea G. Tiemens ${ }^{\star \star}$ \\ Johan Ormel* \\ * Department of Psychiatry, University \\ Medical Center Groningen, Groningen \\ ** Gelderse Roos Institute for \\ Professionalization, Wolfheze \\ THE NETHERLANDS
}

\begin{abstract}
Background and objectives: Depression is often a recurrent or persistent disorder. Since the majority of depressed patients are treated in primary care, it is clear that to improve long-term outcomes more effective treatments in this setting are needed. The goal of this study was to review the strategies used for improvement of routine treatment in terms of their effects on patient outcome.

Methods: We conducted a systematic literature search to identify improvement strategies tested in randomized controlled trials in primary care, reporting at least six months effects on depression course and outcome.

Results: Four strategies were identified: (1) training primary care physicians (PCPs) this appears ineffective (2) supporting PCPs by other professionals - this produces better short term outcomes but does not prevent recurrence (3) organisational quality improvement - this shows improved outcomes at 6 months, and there is some evidence of longer term effectiveness; and (4) recurrence - and chronicity prevention strategies - these have not been shown to be effective.

Conclusion: Since effects of the reviewed strategies generally do not seem to persist over time and no clear superiority over usual care has been demonstrated, we conclude that for improving long-term outcome of depression in primary care new directions or even a novel paradigm is needed.
\end{abstract}




\section{Introduction}

The majority of depressed patients are treated in primary care ${ }^{1}$, but the appropriateness of this situation has been questioned. Especially from a long-term perspective, not all treatment is effective ${ }^{2}$.

Evidence-based, standardized management guidelines for the treatment of depression in primary care have been available since the $1990{ }^{\prime 3}{ }^{3,4}$. Summarized, these recommend a combination of antidepressant medication and brief, supportive counselling and include criteria for patient referral to specialized mental health care. Outcome studies have found that about half of depressed primary care patients recover or improve significantly within a few months. However, many patients do not recover or only partially, while about a fifth has episodes lasting more than a year and the relapse rate is high, in particular in those patients who achieve only partial remission $^{5-7}$. In sum, the need for more effective treatment for patients who do not recover within a few months is clear.

In the present paper, we critically review approaches to improve routine care for depression and ask whether it succeeds in improving long-term outcome ( $\geq$ six months) in primary care patients?

\section{Methods}

\section{Search procedure}

We conducted a systematic literature search. First, we searched in major electronic bibliographical databases, i.e. Medline, Pubmed, PsycLIT, PsycINFO, Current Contents and the Cochrane Library. Central search terms were major depression / depressive episode; primary care treatment; and randomized controlled (clinical) trial. The following terms were added to each of these central terms: course; outcome; chronicity (persistence); recurrence; relapse; remission; recovery; long-term management; psychotherapy; antidepressant medication; relapse prevention; intervention. Secondly, we collected the available professional guidelines and major meta-analyses and reviews published on the subject. Finally, we used reference lists from selected publications.

\section{Selection criteria}

Studies were included if they were:

- randomized controlled trials (RCTs)

- conducted in primary care

- reporting at least six months patient outcome data

- comparing psychological treatments or supportive interventions

- with care as usual (CAU) by the primary care physician

- for adult patients ( $\geq 18$ years),

- with major depression (DSM-IV) or depressive episode (ICD-10).

Studies comparing effectiveness of psychotherapy and pharmacotherapy with CAU were included but not studies that examined effects of antidepressants (AD) only. Several good quality reviews and meta-analyses on this latter subject are available ${ }^{8,9}$. Furthermore, we excluded studies limited to selected patient groups such as the elderly. Finally, publications had to be available in English.

Depression diagnosis had been established by a standardized measure, preferably a structured interview. In the absence of a 
research diagnosis, symptoms assessed by reliable and valid (self-report) questionnaires had to be reported. We required that all interventions, the study design, randomization procedure and treatment assignment, as well as patient recruitment and attrition were described adequately. Also, the main outcome analyses should have covered all patients initially included in the study, hence on an intention-to-treat basis.

\section{Results}

We identified four approaches.

\section{Training primary care physicians}

Historically, the oldest wave of efforts to improve depression outcomes in primary care focused on education and training of primary care physicians (PCPs). However, studies that have evaluated clinical effectiveness of these programs generally show that they are well received but fail to achieve substantial or enduring improvements in depression outcomes ${ }^{10-15}$. For that, more elaborate strategies seem warranted.

\section{Supporting the PCP by other professionals}

Key characteristic of the second strategy to improve treatment of depression in primary care is the involvement of other (mental health) professionals such as psychiatrists, social workers, counsellors, psychologists, and nurses. We identified eight studies about this approach that fitted our criteria: 1 on consultation liaison psychiatry; 4 studies on counselling and 3 on psychotherapy (see Table I).

\section{Consultation Liaison Psychiatry (CLP)}

Patients in the CLP condition in the study of Katon et al. ${ }^{16}$ had alternating visits with the PCP and a psychiatrist, receiving education and antidepressant monitoring. PCPs in the CLP-arm were also offered education and case by case consultation. Forty-two percent of included patients were diagnosed with MD. After seven months, more of the patients receiving CLP (75\%) had improved than usual care patients (44\%). However, at 19 months no such difference was left ${ }^{17,18}$.

\section{Counselling}

All four counselling studies were from the United Kingdom (UK). Counsellors came from diverse professional backgrounds and used a variety of models and techniques, from "reflective listening to enable the patient to resolve their own difficulties"19, to psychotherapeutic techniques, more directive advise and the provision of practical help.

Only in the study of Simpson et al. ${ }^{20}$, counselling was more effective than usual care; $52 \%$ patients recovered in the counselling condition and $36 \%$ in the usual care condition. Compared to the other three studies, this study included only patients with chronic depression and the intervention was psychodynamic counselling, where the other studies offered more general forms of counselling, called social work counselling ${ }^{21,22}$, non-directive counselling $^{23,24}$ and generic counselling ${ }^{25}$.

Two of these counselling studies incorporated patient preference arms in the design, but in neither did this choice of treatment confer additional benefit on outcome.

\section{Psychotherapy}

We selected four psychotherapy studies, including the counselling study of Ward et al. ${ }^{23}$; two were carried out in the UK and two in the United States of America (USA). 


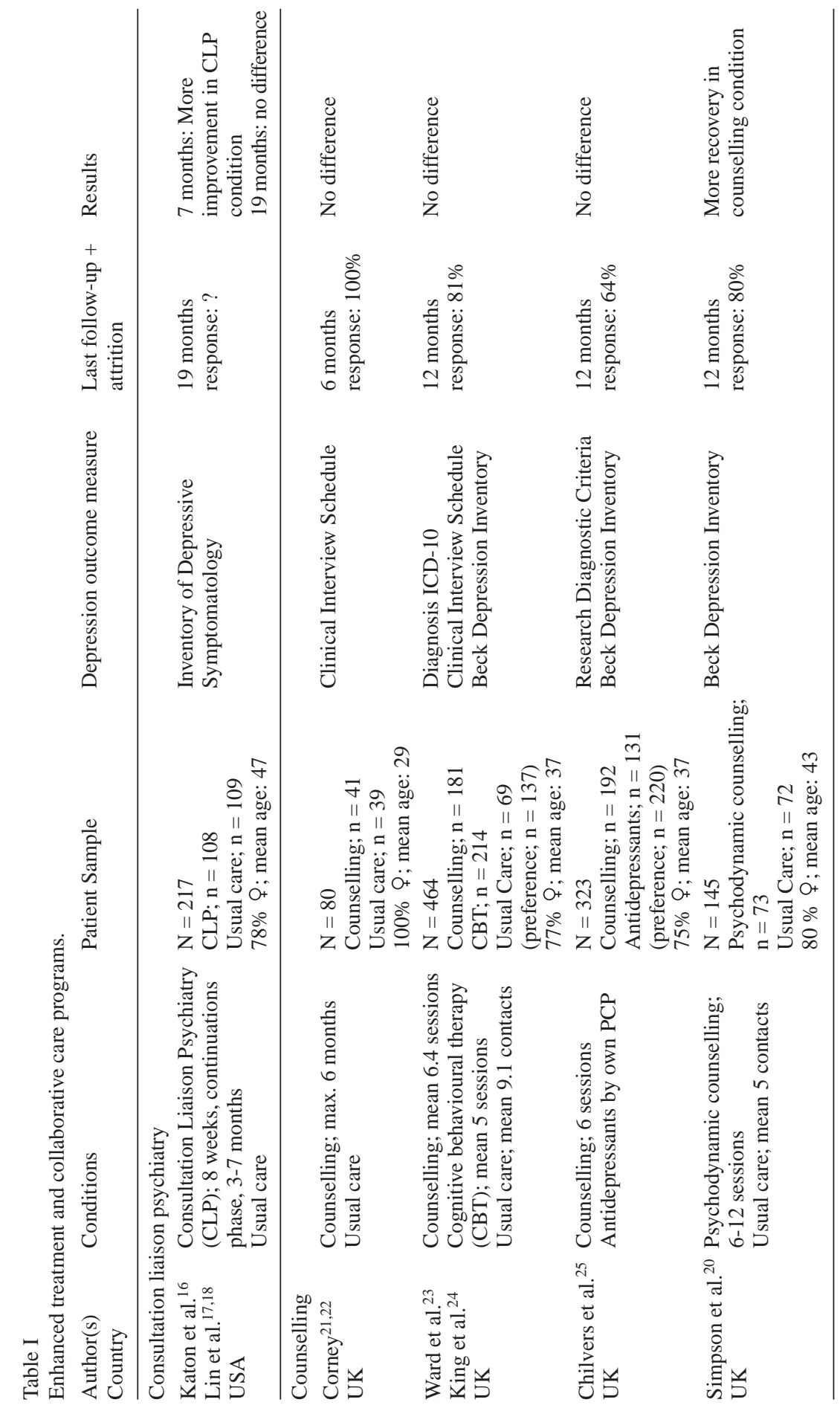




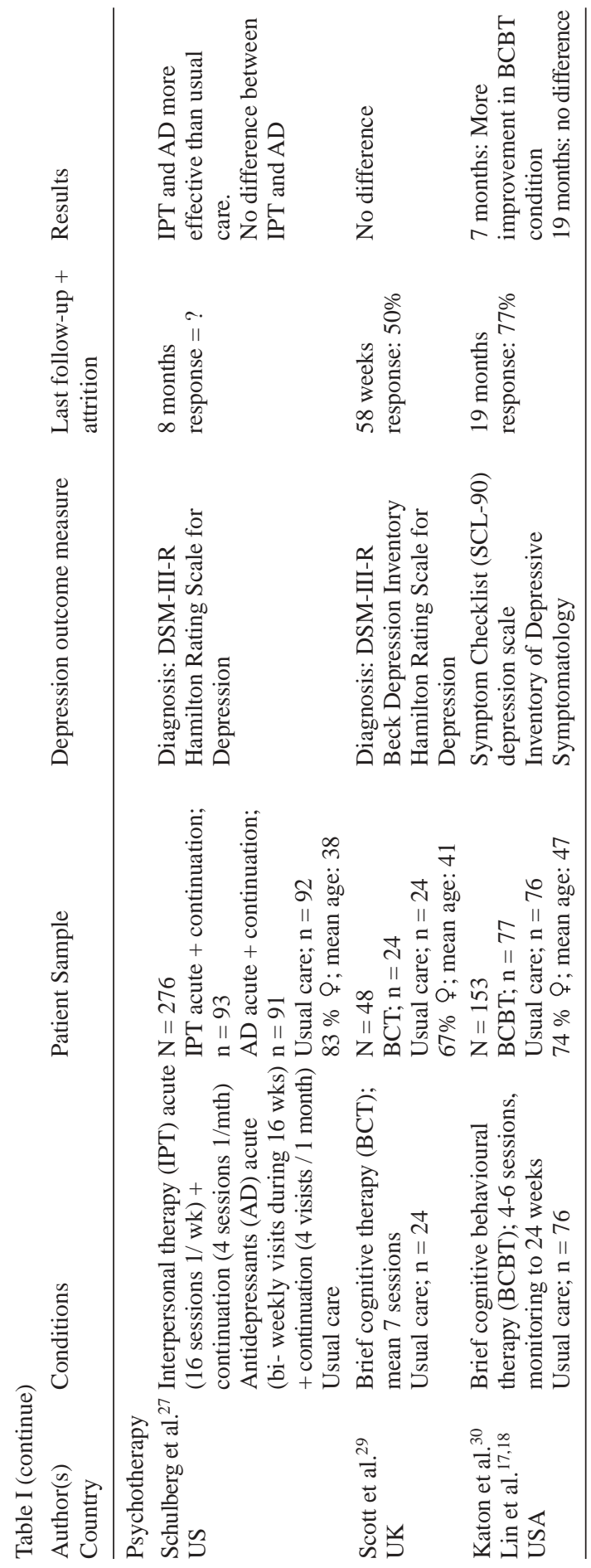


Therapies that were tested are: interpersonal therapy (IPT; 1 study), cognitive therapy (CT; 1 study) \& cognitive behavioural therapy (CBT; 2 studies).

IPT is aimed at improving interpersonal skills and learning more effective strategies for dealing with the stressors associated with depression ${ }^{26}$. The study carried out in the USA by Schulberg et al. ${ }^{27,28}$ compared IPT with antidepressants and usual care by the PCP. At eight months follow-up significantly more patients in both the IPT (46\%) condition and the antidepressants (48\%) condition had recovered than in the usual care $(18 \%)$ condition.

CT and CBT aim at modifying negative thoughts and beliefs and thereby also change behaviour that might be dysfunctional and contributing to (maintenance of) depression. Ward et al. ${ }^{23}$ found similar 1-year outcomes for CBT, counselling and usual care. Another British study by Scott and colleagues ${ }^{29}$ demonstrated better outcomes in the CT condition over usual care on the short-term, but not after a year.

In the USA, Katon and co-workers ${ }^{30}$ developed a structured program in which PCPs cooperated with psychologists who provided brief CBT (including a video and book) and monitored antidepressant adherence. $43 \%$ of the patients met criteria for MD. After 7 months more MD-patients in the CBT condition had improved compared to usual care (70\% vs. $42 \%)$. At 19 months, no differences in outcome were left and $37 \%$ of all patients had experienced a relapse $\mathrm{e}^{17,18}$.

\section{Organizational quality improvement}

The need for better coordinated care and for more systematic, active patient follow up to monitor progress over time can be identified as central themes in recent approaches to improve long-term depression outcomes ${ }^{31,32}$. These approaches not only address the contents of depression treatment, but also the context and organization in which this treatment is delivered (see Table II).

Practice support by nurses or care managers

We found four studies in which nurses or care managers actively follow the patients, mainly by telephone, to support patients in adhering to their antidepressant medication, monitor their symptoms, and give feedback to their PCP. Generally, these studies showed that more patients in the experimental conditions improved (varying from 55\% to $60 \%$ ) than in the usual care condition (varying from $38 \%$ to $47 \%$ ). However, in all four studies follow-up time was limited to 6 months.

Some aspects need further attention. In the Nurse Telehealth Care (NTC) study of Hunkeler et al. ${ }^{33}$, additional peer support by trained volunteers was offered in a third condition, but no additional effects were found. In their first study, Simon and colleagues $^{34}$ found that a feedback and care management program (FCM) was more effective than written feedback alone or usual care. However, in their second study ${ }^{35}$, no additional beneficial effects of FCM over usual care were found. Interestingly, patients receiving an FCM version that included brief CBT by telephone, improved more than patients in both other conditions.

Comprehensive practice-level quality improvement strategies

Two studies in the United States report about elaborate practice-level strategies to improve depression management.

In the "Quality Enhancement by Strategic Teaming" ('Quest') strategy $y^{36-38}$ the roles of all members of community primary care 


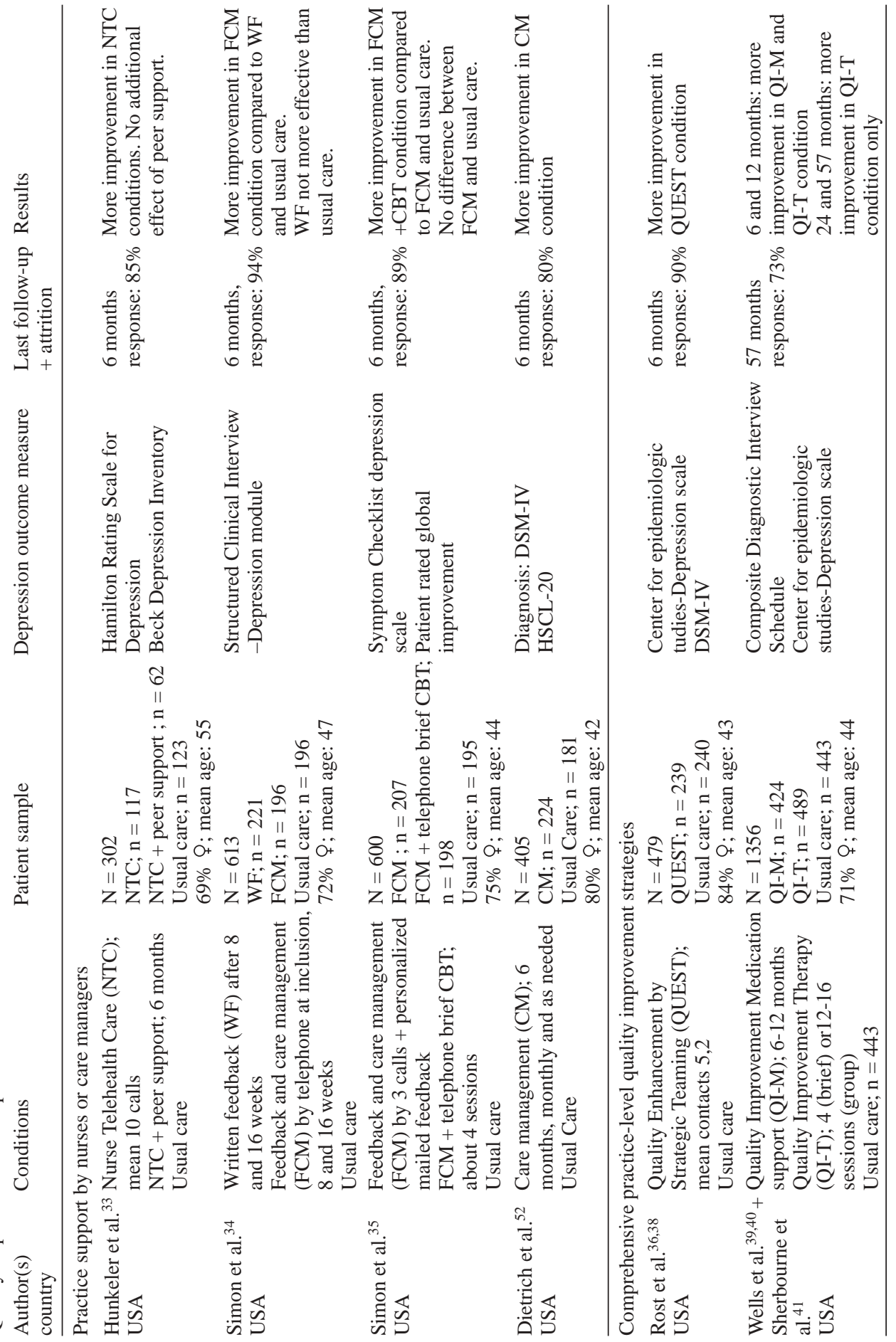


practice teams were redefined: administrative staff was trained to screen and recruit patients meeting criteria for major depression; nurses were trained to be able to provide education and monitor adherence to treatment and progress; and PCPs received a brief training in guideline concordant treatment. At six months follow-up, patients in the QUEST-practices showed more improvement in depressive symptoms than patients treated in usual care settings. However, this was only the case for patients that had started with a new treatment; patients with persistent symptoms despite recent treatment did not benefit.

The quality improvement (QI) program in the Partners in Care study ${ }^{39-41}$ included: a 2day basic depression management training package to primary care providers, nurses and therapists; enhanced resources for antidepressant treatment (QI-M; with support of a nurse care manager ) or (individual or group) CBT (QI-T). After one year, both QI interventions had reduced depression more than usual care: $42 \%$ of QI-patients compared with $52 \%$ of UC-patients (still) suffered from major depression and/ or dysthymia. At the 2- and 5year follow-up the therapy version of QI (i.e.: CBT) was found to have more sustained benefits than both other conditions. However, interpretation of these results is complicated. By design, this study did not randomly assign patients to specific treatments but rather randomized opportunities for getting appropriate depression care ${ }^{42}$, so that actual treatment that patients received may not have been that different across conditions.

\section{Interventions aimed at reduction of relapse, recurrence and persistence of depression}

Risk-reduction strategies usually focus on factors directly associated with the disorder (such as residual depressive symptoms) or at enhancing protective aspects or circumstances, including self-management and coping. We found four studies, three from the USA, testing this strategy. The studies are summarized in Table III.

Katon and co-workers ${ }^{43-45}$ conducted two studies. One was targeted at patients with persistent symptoms of depression, who received CLP as described in 3.2. While this strategy was more effective than usual care on the short run, no differences were present after two years. The other intervention was aimed at patients who were recovered but considered to be at high risk for relapse. They received a Relapse Prevention Program (RPP) that focused on the continued use of antidepressants, systematic monitoring of symptoms and the development of a personal relapse prevention $\operatorname{plan}^{46}$. Similar relapse rates $(35 \%)$ over 1 year show that the RPP did not result in improved outcome over usual care.

In the Netherlands, Smit and colleagues ${ }^{47,48}$ replicated the RPP study of Katon et al. with an adapted version (the Depression Recurrence Prevention (DRP) Program ${ }^{49}$ ) aimed at 'new' as well as chronic patients. This enhanced care did not lead to better 6months outcomes compared to usual care. Furthermore, there were no indications for any surplus effects of addition of a psychiatric consultation or CBT to the DRP.

Finally, Rost et al. ${ }^{50}$ evaluated effects of enhanced care (EC) targeted at patients still reporting many depressive symptoms after being treated for 6 months. The intervention was matched to the persistence of depression, with patients reporting more symptoms contacted more frequently by care managers monitoring symptoms and antidepressant use and providing feedback to the PCPs. Patients whose symptoms persisted were encouraged to visit the practice. By 24 months, more EC than usual care patients ( $74 \%$ vs. $41 \%$ ) met criteria for remission. 


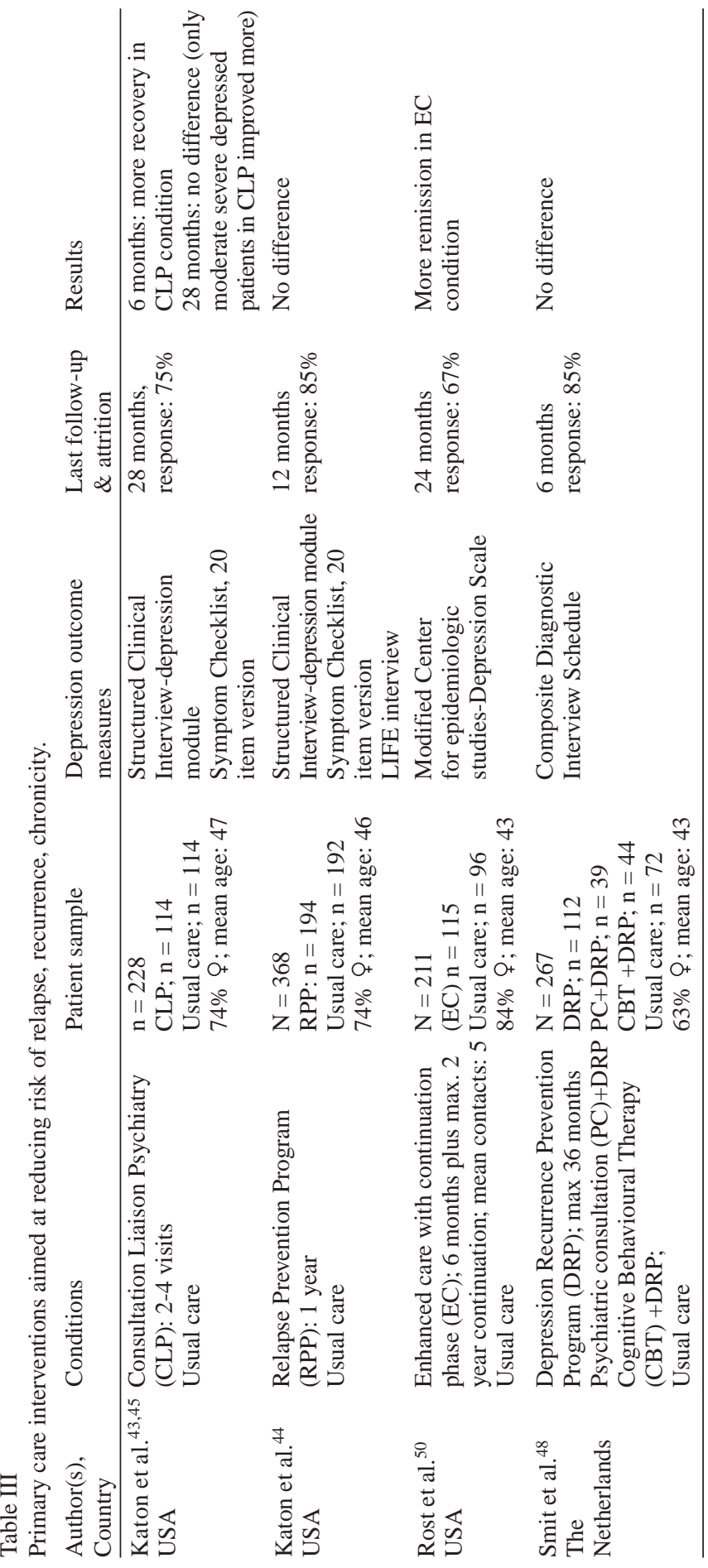




\section{General conclusions}

Given that major depression often follows a chronic course, with few people having only one isolated episode and primary care in many cases being the main treatment setting, the core question we wanted to answer with this systematic literature search was: what is an effective method to improve long-term outcome for depression in primary care? Summing up the results of the reviewed studies, we can conclude that:

1. Training of PCPs does not achieve improvements in long-term depression outcome.

2. Enhanced and collaborative care may result in improved short-term outcomes, but do not appear to prevent recurrence.

3. Quality improvement strategies do show improved outcomes at 6 months, and there is some evidence of longer term effectiveness.

4. It is as yet inconclusive whether tailored interventions aimed at prevention of relapse, recurrence and chronicity succeed in improved long-term depression outcome.

Unfortunately, we did not find a clear answer. Most studies have not demonstrated success in the prevention of chronicity. Maybe new directions are needed to resolve the problems. Parker ${ }^{51}$ has stated that the present concept of major depression had led to sterility in depression research and clinical practice. For instance, it has become the convention to neglect all differentiations which exist among patients. However, findings in this review illustrate how often different results are found for different subgroups of patients in terms of severity and duration. Diversity goes further than that and also exists in the way patients (and their loved ones) deal with their depression and if and where they seek help for their problems. Therefore, we conclude that to improve the long-term outcome of depression in primary care, we should not persist in doing 'more of the same', but instead search for new directions or even a novel paradigm.

\section{References}

1. Spijker J, Bijl RV, de Graaf R, Nolen WA. Care utilization and outcome of DSM-III-R major depression in the general population. Results from the Netherlands Mental Health Survey and Incidence Study (NEMESIS). Acta Psychiatr Scand 2001; 104: 19-24.

2. Von Korff M, Goldberg D. Improving outcomes in depression. BMJ 2001; 323: 948-949.

3. Agency for Health Care Policy and Research. Depression Guideline Panel. Rockville: US Dept of Health and Human Services; 1993.

4. National Institute for Clinical Excellence. Clinical guideline 23. London: National Institute for Clinical Excellence; 2004.

5. Ormel, J. Oldehinkel AJ, Brilman E, van den Brink $\mathrm{W}$. Outcome of depression and anxiety in primary care. A three-wave 3 1/2-year study of psychopathology and disability. Arch Gen Psychiatry 1993; 50: 759-766.

6. Simon GE. Long-term prognosis of depression in primary care. Bull World Health Organ 2000; 78:439-445.

7. Os TW, van den Brink RH, van der Meer K, Ormel J. The care provided by general practitioners for persistent depression. Eur Psychiatry 2006; 21: 87-92.

8. Simon GE. Evidence review: efficacy and effectiveness of antidepressant treatment in primary care. Gen Hosp Psychiatry 2002; 24: 213-224.

9. MacGillivray S, Arroll B, Hatcher S, Ogston S, Reid I, Sullivan F et al. Efficacy and tolerability of selective serotonin reuptake inhibitors compared with tricyclic antidepressants in depression treated in primary care: systematic review and meta-analysis. BMJ 2003; 326: 1014.

10. Lin E, Katon W, Simon G, VonKorff M, Bush T, Rutter $\mathrm{C}$ et al. Achieving guidelines for the treatment of depression in primary care: is physician education enough? Med Care 1997; 35: 831-842.

11. Tiemens BG, Ormel J, Jenner JA, van der Meer K, van Os TW, van den Brink RH et al. Training primary-care physicians to recognize, diagnose and manage depression: does it improve patient outcomes? Psychol Med 1999; 29: 833-845. 
12. Worrall G, Angel J, Chaulk P, Clarke C, Robbins M. Effectiveness of an educational strategy to improve family physicians' detection and management of depression: a randomized controlled trial. CMAJ 1999; 161: 37-40.

13. Brown C, Schulberg HC, Prigerson HG. Factors associated with symptomatic improvement and recovery from major depression in primary care patients. Gen Hosp Psychiatry 2000; 22: 242-250.

14. Thompson C, Kinmonth AL, Peveler R, Stevens A, Ostler KJ, Pickering RM et al. Effects of a clinical-practice guideline and practice-based education on detection and outcome of depression in primary care: Hampshire Depression Project randomised controlled trial. Lancet 2000; 355: 185-191.

15. Os TWDP van, Ormel J, van den Brink RHS, Jenner $\mathrm{J}$, Tiemens BG, van der Doorn $\mathrm{W}$ et al. Training primary care physicians improves the management of depression. Gen Hosp Psychiatry 1999; 21: 168-176.

16. Katon W, VonKorff M, Lin E, Walker E, Simon GE, Bush $\mathrm{T}$ et al. Collaborative management to achieve treatment guidelines. Impact on depression in primary care. JAMA 1995; 273: 1026-1031.

17. Lin EH, Katon WJ, VonKorff M, Russo JE, Simon GE, Bush TM et al. Relapse of depression in primary care. Rate and clinical predictors. Arch Fam Med 1998; 7: 443-449.

18. Lin EH, Simon GE, Katon WJ, Russo JE, Von Korff M, Bush TM et al. Can enhanced acute-phase treatment of depression improve long-term outcomes? A report of randomized trials in primary care. Am J Psychiatry 1999; 156: 643-645.

19. Bower P, Rowland N, Mellor C, Heywood P, Godfrey C, Hardy R. Effectiveness and cost effectiveness of counselling in primary care. Cochrane Database Syst Rev 2002; (1): CD001025

20. Simpson S, Corney R, Fitzgerald P, Beecham J. A randomized controlled trial to evaluate the effectiveness and cost-effectiveness of psychodynamic counselling for general practice patients with chronic depression. Psychol Med 2003; 33: 229-239.

21. Corney RH. The effectiveness of attached social workers in the management of depressed female patients in general practice. Psychol Med Monogr Suppl 1984; 6: 1-47.

22. Corney RH. The effectiveness of attached social workers in the management of depressed female patients in general practice. Br J Psychiatry 1987; 151: 652-659.

23. Ward E, King M, Lloyd M, Bower P, Sibbald B, Farrelly $\mathrm{S}$ et al. Randomised controlled trial of non-directive counselling, cognitive-behaviour therapy, and usual general practitioner care for patients with depression. I: clinical effectiveness. BMJ 2000; 321:1383-1388.
24. King M, Sibbald B, Ward E, Bower P, Lloyd M, Gabbay $\mathrm{M}$ et al. Randomised controlled trial of non-directive counselling, cognitive-behaviour therapy and usual general practitioner care in the management of depression as well as mixed anxiety and depression in primary care. Health Technol Assess 2000; 4(19): 1-83.

25. Chilvers C, Dewey M, Fielding K, Gretton V, Miller P, Palmer B et al. Antidepressant drugs and generic counselling for treatment of major depression in primary care: randomised trial with patient preference arms. BMJ 2001; 322: 1-5.

26. Weissman MM, Markowitz JC. Interpersonal psychotherapy. Current status. Arch Gen Psychiatry 1994; 51 : 599-606.

27. Schulberg HC, Block MR, Madonia MJ, Scott CP, Rodriguez E, Imber SD et al. Treating major depression in primary care practice. Eight-month clinical outcomes. Arch Gen Psychiatry 1996; 53: 913-919.

28. Schulberg HC, Pilkonis PA, Houck P. The severity of major depression and choice of treatment in primary care practice. J Consult Clin Psychol 1998; 66: 932-938.

29. Scott C, Tacchi MJ, Jones R, Scott J. Acute and oneyear outcome of a randomised controlled trial of brief cognitive therapy for major depressive disorder in primary care. Br J Psychiatry 1997; 171: 131-134.

30. Katon W, Robinson P, VonKorff M, Lin E, Bush T, Ludman $\mathrm{E}$ et al. A multifaceted intervention to improve treatment of depression in primary care. Arch Gen Psychiatry 1996; 53: 924-932.

31. Badamgarav E, Weingarten SR, Henning JM, Knight K, Hasselblad V, Gano A, Jr. et al. Effectiveness of disease management programs in depression: a systematic review. Am J Psychiatry 2003; 160: 2080-2090.

32. Gensichen J, Beyer M, Muth C, Gerlach FM, Von Korff M, Ormel J. Case management to improve major depression in primary health care: a systematic review. Psychol Med 2006; 36: 7-14.

33. Hunkeler EM, Meresman JF, Hargreaves WA, Fireman B, Berman WH, Kirsch AJ et al. Efficacy of nurse telehealth care and peer support in augmenting treatment of depression in primary care. Arch Fam Med 2000; 9: 700-708.

34. Simon GE, VonKorff M, Rutter C, Wagner E. Randomised trial of monitoring, feedback, and management of care by telephone to improve treatment of depression in primary care. BMJ 2000; 320: 550-554.

35. Simon GE, Ludman EJ, Tutty S, Operskalski B, Von Korff M. Telephone psychotherapy and telephone care management for primary care patients starting antidepressant treatment: a randomized controlled trial. JAMA 2004; 292: 935-942. 
36. Rost K, Nutting PA, Smith J, Werner JJ. Designing and implementing a primary care intervention trial to improve the quality and outcome of care for major depression. Gen Hosp Psychiatry 2000; 22: 66-77.

37. Rost K, Duan N, Rubenstein LV, Ford DE, Sherbourne CD, Meredith LS et al. The Quality Improvement for Depression collaboration: general analytic strategies for a coordinated study of quality improvement in depression care. Gen Hosp Psychiatry 2001; 23: 239-253.

38. Rost K, Nutting P, Smith J, Werner J, Duan N. Improving depression outcomes in community primary care practice: a randomized trial of the quEST intervention. Quality Enhancement by Strategic Teaming. J Gen Intern Med 2001; 16: 143-149.

39. Wells KB, Sherbourne C, Schoenbaum M, Duan N, Meredith L, Unutzer J et al. Impact of disseminating quality improvement programs for depression in managed primary care: a randomized controlled trial. JAMA 2000; 283: 212-220.

40. Wells K, Sherbourne C, Schoenbaum M, Ettner S, Duan N, Miranda J et al. Five-year impact of quality improvement for depression: results of a group-level randomized controlled trial. Arch Gen Psychiatry 2004; 61: 378-386.

41. Sherbourne CD, Wells KB, Duan N, Miranda J, Unutzer J, Jaycox L et al. Long-term effectiveness of disseminating quality improvement for depression in primary care. Arch Gen Psychiatry 2001; 58: 696-703.

42. Roth A, Fonagy P. What Works for Whom? A Critical Review of Psychotherapy Research. 2nd ed. New York: Guildford Publications Inc; 2004.

43. Katon W, Von-Korff M, Lin E, Simon G, Walker E, Unutzer J et al. Stepped collaborative care for primary care patients with persistent symptoms of depression: a randomized trial. Arch Gen Psychiatry 1999; 56: 1109-1115.

44. Katon W, Rutter C, Ludman EJ, VonKorff M, Lin E, Simon G et al. Stepped collaborative care for primary care patients with persistent symptoms of depression: a randomized trial. Arch Gen Psychiatry 2001; 58: 241-247.
45. Katon W, Russo J, Von Korff M, Lin E, Simon G, Bush $\mathrm{T}$ et al. Long-term effects of a collaborative care intervention in persistently depressed primary care patients. J Gen Intern Med 2002; 17: 741-748.

46. Ludman E, Von Korff M, Katon W, Lin E, Simon G, Walker E et al. The design, implementation, and acceptance of a primary care-based intervention to prevent depression relapse. Int J Psychiatry Med 2000; 30: 229-245.

47. Smit A, Tiemens BG, Ormel J, Kluiter H, Jenner JA, Meer Kvd et al. Short-term effects of enhanced treatment for depression in primary care: results from a randomized controlled trial. Primary Care and Community Psychiatry 2005; 10: 39-49.

48. Smit A, Kluiter H, Conradi HJ, van der Meer K, Tiemens BG, Jenner JA et al. Short-term effects of enhanced treatment for depression in primary care: results from a randomized controlled trial. Psychol Med 2006; 36: 15-26.

49. Tiemens BG, Jenner JA, Kluiter H, Meer Kvd. The Depression Recurrence Prevention (DRP) Program. Seattle: Time Life Medical; 1998.

50. Rost K, Nutting P, Smith JL, Elliott CE, Dickinson M. Managing depression as a chronic disease: a randomised trial of ongoing treatment in primary care. BMJ 2002; 325: 934 .

51. Parker G. Beyond major depression. Psychol Med 2005; 35(4): 467-474.

52. Dietrich AJ, Oxman TE, Williams JW, Jr., Schulberg $\mathrm{HC}$, Bruce ML, Lee PW et al. Re-engineering systems for the treatment of depression in primary care: cluster randomised controlled trial. BMJ 2004; 329: 602.

Address for correspondence:

Annet Smit

Gelderse Roos Institute for Professionalization (GRIP)

P.O. Box 27,6870 AA Renkum, The Netherlands

Tel: +31-26 4833325

Fax:+31-26 4833336

Email: a.smit@degelderseroos.nl 